\title{
Experimental investigation of a plate heat exchanger model for lithium bromide absorption chillers: first results
}

\author{
Konstantin Stepanov ${ }^{1, *}$, Dmitry Mukhin ${ }^{1}$, and Olga Volkova ${ }^{2}$ \\ ${ }^{1}$ Institute of Thermophysics SB RAS, 1, Lavrentyev Ave, Novosibirsk 630090, Russia \\ ${ }^{2}$ Saint Petersburg ITMO University, 9, Lomonosova st., Saint Petersburg 197101, Russia
}

\begin{abstract}
In this paper the results of thermal-hydraulic tests of a sample of a perspective plate heat exchanger under the conditions of LBAHT is described. Working opportunity of the sample working under conditions of LBAHT has been confirmed by this research.
\end{abstract}

\section{Introduction}

Now, the cost reduction and the energy efficiency enhancement of lithium bromide absorption heat transformers (LBAHT) are very important problems.

The enhancement of economic and exploitation characteristics are possible by increasing of solution heat exchanger efficiency. In this regard, as an alternative to shelltube exchangers plate type exchangers are increasingly used for recuperation of heat of weak and strong solution in LBAHT.

This is due to the fact that at the same heating surface the plate heat exchanger has a relatively high energy efficiency, compactness and significantly lower capacity for an aqueous solution of lithium bromide salt is absorbent continuously rising in price.

In this way, the use of a plate heat exchanger in the construction of LBAHT is of undoubted interest because leads to a significant reduction in capital costs for the manufacture of LBAHT and increased energy efficiency in the operation of LBAHT.

There is high operational reliability demands such as tightness and corrosion resistance are subjected to heat exchangers of LBAHT. For this, sealed, brazed or welded heat exchangers with plates of corrosion-resistant material are usually used.

The relevance of the experimental study is due to the fact that there is no universal dependence for the analytical evaluation of thermal hydraulic characteristics depending on the fluid flow regimes in the channel for complicated configurations of the heat exchange surfaces [1-3].

\section{Experimental setup}

\footnotetext{
* Corresponding author: stepanov ki@mail.ru
} 
Within the framework of this project an experimental setup for the study of the thermal and hydraulic characteristics of the heat exchange equipment of LBAHT has been developed and manufactured. Schematic diagram of the setup is shown in Fig.1.

$\mathrm{LiBr}$ solution with 55\% mass concentration are circulated through closed loop through the test model of plate heat exchanger 1, plate heat exchanger for cooling of LiBr solution 5, pre-heater of $\mathrm{LiBr}$ solution 3. To circulation of $\mathrm{LiBr}$ solution the $\mathrm{LiBr}$ circulation pump 2 is used. Flow rate of $\mathrm{LiBr}$ solution is regulated with adjusting valve 4 and controlled with flow-meter 9.

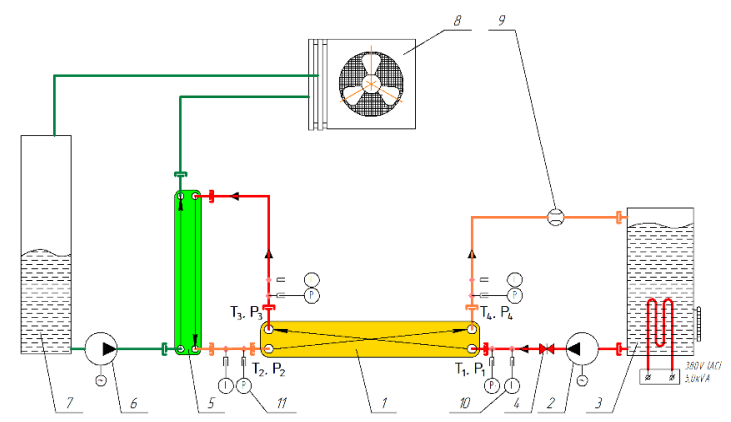

Fig. 1. Schematic diagram of the for the study of the thermal and hydraulic characteristics of the heat exchange equipment of LBAHT: 1 - test model of plate heat exchanger; 2 - LiBr circulation pump; 3 - pre-heater of $\mathrm{LiBr}$ solution; 4 - adjusting valve; 5 - plate heat exchanger for cooling of $\mathrm{LiBr}$ solution; 6 - pump of cooling liquid; 7 - tank of cooling liquid; 8 - air-cooled heat erxchanger; 9 flow-meter; 10 - temperature sensor; 11 - pressure sensor.

Heating and temperature adjusting of $\mathrm{LiBr}$ solution are performed in pre-heater 3 with resistive heater element. Heat capacity adjusting is performed by changing of voltage.

Cooling of $\mathrm{LiBr}$ solution are performed in heat exchanger 5 by water. Circulation and cooling of water are performed by the pump of cooling liquid 6, tank of cooling liquid 7 and air-cooled heat exchanger 8. Cooling capacity adjusting is performed by changing of speed of fan by frequency controller.

Measure of temperature difference through the test model is performed with resistive temperature converter Pt100. Measure of pressure drop (hydraulic resistance) - with pressure sensors with current signal 4-20 MA.

\subsection{Test model of plate heat exchanger}

Construction of the test model of plate heat exchanger is shown on Fig. 2.

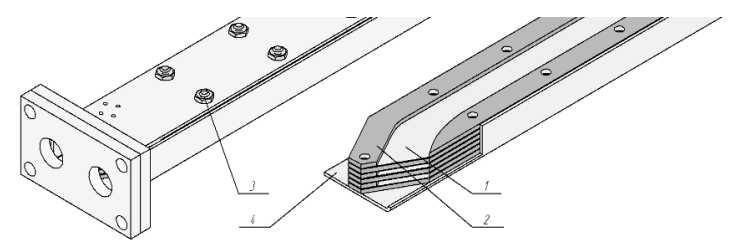

Fig. 2. Appearance of the test model.

1 - flat plate; 2 - gasket, 3 - bolted joints; 4 - part of housing.

The test model is consisted from flat plates and gaskets. Distance between plates " $h$ " is $3 \mathrm{~mm}$. The channel width " $b$ " is $20 \mathrm{~mm}$, the length is $1000 \mathrm{~mm}$. The number of passes is 1 , the number of channels in the pass is 3 . The package of plates and gaskets is connected by means of glue and is tightened by bolted joints. As a result of joining plates and gaskets slot channels of rectangular cross section are formed. 


\section{Test results}

The investigation of hydraulic and heat exchange characteristics of plate heat exchanger were conducted under conditions of heat recuperation of $\mathrm{LiBr}$ solution with concentration $55 \%$ (mass.).

Experiments has been carried out by scale imitation of processes of heat recuperation of $\mathrm{LiBr}$ solution under conditions of LBAHT. For this at the outlet of the pre-heater 3 temperature of «strong» solution was maintained within from 85 to $90{ }^{\circ} \mathrm{C}$. Temperature of «weak» solution was maintained within from 35 to $40^{\circ} \mathrm{C}$ at the outlet of the heat exchanger 5.

Dependences of the pressure drop $\Delta \mathrm{P}$ and the overall heat transfer coefficient on the Reynolds number in a 3 mm-height rectangular channel are shown on Fig. 3.

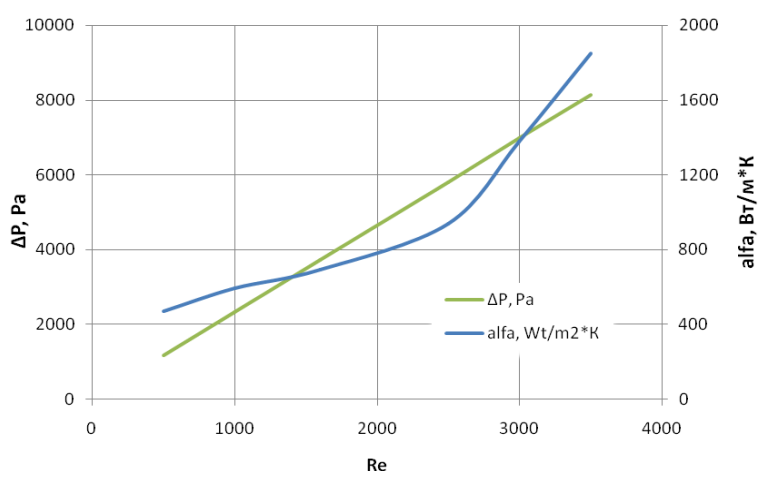

Fig. 3. Pressure drop and overall haet transfer coefficient depending on Reynolds number of 55\% $\mathrm{LiBr}$ solution.

Reynolds number is determined as

$$
\operatorname{Re}=\vartheta_{L i B r} \cdot d_{e} \cdot v_{L i B r}^{-1}
$$

where " $\vartheta_{L i B r}$ " is flow rate in channel, " $v_{L i B r}$ "is the kinematic viscosity of $\mathrm{LiBr}$ solution, " $d_{e}$ " is the equivalent diameter of a rectangular channel:

$$
d_{e}=\frac{2 \cdot h \cdot b}{h+b} \cong 2 \cdot h,(\text { when } b>>h)
$$

Mean pressure drop " $\Delta P$ ” was found as:

$$
\Delta P=\frac{\left(P_{1}-P_{3}\right)+\left(P_{2}-P_{4}\right)}{2}
$$

The intensity of the heat exchange process was determined by solving the system of equations (4)-(6)

$$
\begin{aligned}
& Q_{h}=G \cdot c_{p} \cdot\left(T_{1}-T_{3}\right) \\
& Q_{c}=G \cdot c_{p} \cdot\left(T_{2}-T_{4}\right) \\
& Q_{h} \cong Q_{c}=Q
\end{aligned}
$$

In the equations (4)-(5), " $G$ " is the mass flow rate of the hot and cold fluids, " $T$ " is the inlet and outlet temperature, " $c_{p}$ " is the specific heat capacity

Heat load of plate heat exchanger was calculated as:

$$
Q=K \cdot F_{H E} \cdot \Delta T_{L M T D}
$$

where " $F_{H E}$ " is area of plate heat exchanger, " $\Delta T_{L M T D}$ " is the temperature difference, " $K$ " is the overall heat transfer coefficient: 


$$
\frac{1}{K}=\frac{1}{\alpha_{1}}+\frac{\delta}{\lambda}+\frac{1}{\alpha_{2}}
$$

In the above equation " $\lambda$ " is the thermal conductivity of the plate, " $\delta$ " is the thickness of the plate, " $\alpha_{1}$ " is the cold liquid, and " $\alpha_{2}$ " is the hot liquid.

Mean-logarithmic temperature difference between hot stream and cold stream was calculated as:

$$
\Delta T_{L M T D}=\frac{\left(T_{1}-T_{3}\right)-\left(T_{4}-T_{2}\right)}{\ln \left(\left(T_{1}-T_{3}\right) /\left(T_{4}-T_{2}\right)\right)}
$$

«alfa» has been determined guided by the following assumption (8):

$$
\alpha_{1} \cong \alpha_{2}=\text { alfa }
$$

Assumption (10) was made due to the complete geometric equality of the "hot" and "cold" channels of the heat exchanger and the fact that the same fluid circulated in the channels. The correction for changing the properties of the $\mathrm{LiBr}$ solution was not taken into account.

So, «alfa» is

$$
\text { alfa }=\frac{2}{\frac{1}{K_{1}}-\frac{\delta}{\lambda}} \approx 2 \cdot K
$$

\section{Conclusions}

The tests of the experimental sample proved the functionality of the chosen design under conditions of operation with an aqueous solution of lithium bromide. The results are well agreed with the estimated calculation [5].

Thus, plate heat exchanger with flat plates can be an alternative to a shell-tube heat exchanger of LBAHT, because plate heat exchangers having satisfactory thermo-hydraulic characteristics have a significantly lower volume of an absorbent.

Further work will be devoted to improving the thermal and hydraulic characteristics of the plate heat exchanger for LBAHT: plates containing convex-concave turbulence structures with different hydraulic channel diameters will be tested.

This work was supported by the Russian Foundation for Basic Research (RFBR) through the project №17-48-543278\18.

\section{References}

1. De Vega M., Performance of a $\mathrm{LiBr}$-water absorption chiller operating with plate heat exchangers / M. De Vega, J.A. Almendros-Ibanez, G. Ruiz // Energy Conversion and Management, 2006. — 47. — P. 3393-3407.

2. Jeong, J.Y., Impact of plate design on the performance of welded type plate heat exchangers for sorption cycles / J.Y. Jeong, H.K. Hong, S.K. Kim, Y.T. Kang // International Journal of Refrigeration, 2009. - Vol. 32 (4). - P. 705-711.

3. Kwon Y.H. Heat Transfer and Pressure Drop Characteristics of Nanofluids in a Plate Heat Exchanger / Y.H. Kwon, D. Kim, C.G. Li, J.K. Lee, D.S. Hong, J.G. Lee, S.H.Lee, Y.H.Cho, and S. H. Kim // Journal of Nanoscience and Nanotechnology Vol. 11, 5769-5774, 2011.

4. ASHRAE, Handbook of Fundamentals. Atlanta, 1997. 
5. Stepanov K. I., Mukhin D. G., Mironova N. V., Baranenko A. V., Volkova O. V. Plate heat exchangers in absorption lithium bromide thermal transformers. Vestnik Mezhdunarodnoi akademii kholoda. 2018. No 2. p. 13-21. 